\title{
ON THE NON-COMMUTING GRAPH OF A GROUP
}

\author{
BEHNAZ TOLUE
}

\begin{abstract}
In this paper, groups whose non-commuting graphs are $k$-apex for $1 \leq k \leq 5$ are classified. The 1-planarity of the non-commuting graph for an AC-group $G$ is discussed. Moreover, the $k$-connectivity of the non-commuting graph is verified, for $k \leq 6$. Finally, some properties of the line graph of the non-commuting graph of a group are studied.
\end{abstract}

MSC 2010. Primary 05C25, 05C10, 05C76; Secondary $20 \mathrm{~B} 05$.

Key words. Apex graph, connected graph, non-commuting graph.

\section{REFERENCES}

[1] A. Abdollahi, S. Akbari and H.R. Maimani, Non-commuting graph of a group, J. Algebra, 298 (2006), 468-492.

[2] J.A. Bondy and U.S.R. Murty, Graph Theory with Applications, Elsevier Science Publishing, New York, 1976.

[3] J. Czap and D. Hudàk, 1-planarity of complete multipartite graphs, Discrete Appl. Math., 160 (2012), 505-512.

[4] I. Fabrici and T. Madaras, The structure of 1-planar graph, Discrete Math., 307 (2007), 854-865.

[5] GAP, GAP - Groups, Algorithms and Programming, http://www.gap-system.org, 2002.

[6] D.L. Greenwell and R.L. Hemminger, Forbidden subgraphs for graphs with planar line graphs, Discrete Math., 2 (1972), 31-34.

[7] F. Harary and C.St.J.A. Nash-Williams, On Eulerian and Hamiltonian graphs and line graphs, Canad. Math. Bull., 8 (1965), 701-710.

[8] B.H. Neumann, A problem of Paul Erdös on groups, J. Aust. Math. Soc., 21 (1976), 467-472.

[9] L. Pyber, The number of pairwise noncommuting elements and the index of the centre in a finite group, J. Lond. Math. Soc. (2), 35 (1987), 287-295.

[10] D.M. Rocke, p-groups with abelian centralizers, Proc. Lond. Math. Soc. (3), 30 (1975), $55-75$.

[11] B. Tolue, The non-centralizer graph of a finite group, Math. Rep. (Bucur.), 17 (67) (2015), 265-275.

[12] H.J. Veldman, Existence of dominating cycles and pathes, Discrete Math., 43 (1983), 281-296.

[13] Y. Wei, X. Ma and K.Wang, Rainbow connectivity of the non-commuting graph of a finite group, J. Algebra Appl., 15 (2016), 1650127.

The author thanks the referee for his helpful comments and suggestions.

DOI: $10.24193 /$ mathcluj.2019.2.09 
Received July 9, 2018

Accepted November 7, 2018
Hakim Sabzevari University Department of Pure Mathematics Sabzevar, Iran

E-mail: b.tolue@gmail.com b.tolue@hsu.ac.ir 